\title{
Review
}

\section{Caspase activation without death}

\author{
A Zeuner ${ }^{1}$, A Eramo ${ }^{2}$, C Peschle ${ }^{2,3}$ and R De Maria ${ }^{*, 1}$ \\ 1 Institute of General Pathology, University of Catania, Catania, Italy \\ 2 Thomas Jefferson University, Kimmel Cancer Center, Bluemle Life Sciences \\ Building, Philadelphia, USA \\ ${ }^{3}$ Department of Hematology-Oncology, Istituto Superiore di Sanità, Rome, Italy \\ * Corresponding author: R De Maria, Institute of General Pathology, University \\ of Catania, Via Androne 83, 95124 Catania, Italy. \\ Tel: +39 0649903 121; Fax: +39 0649387 087; E-mail: rdemaria@tin.it
}

Received 3.5.99; revised 18.8.99; accepted 7.9.99

Edited by G Melino

\begin{abstract}
Since molecular cloning of the C. elegans ced-3 gene revealed its homology with mammalian IL-1 $\beta$-converting enzyme, ${ }^{1} 14$ members of the caspase family have been identified, which have often been involved as mediators of one or more phases of the apoptotic process. ${ }^{2,3}$ However, an over-simplified role of these proteases may be insufficient to explain the usually constitutive expression of such a large and complex family of enzymes, many of which display overlapping specificity. In addition to the well-established role of caspase- 1 in the production of active IL-1 $\beta$ and IL-18 in inflammation, ${ }^{4}$ an increasing number of reports has recently suggested that caspases may have a function outside of apoptosis. In this review, the situations in which cells survive despite the presence of activated caspases in their cytoplasm will be examined and discussed, with the intent to gather all recent advances in this new field that promises to be a focus for caspase research in the near future.
\end{abstract}

Keywords: apoptosis; survival; differentiation; interleukin; hematopoiesis; CD95 (Fas/Apo-1)

Abbreviations: IL, interleukin; caspase, cysteinyl aspartatespecific protease

\section{Proinflammatory role of caspases: processing of IL-1 $\beta$ and IL-18 by ICE}

IL-1 $\beta$-converting enzyme ICE (now caspase-1) was originally identified as the protease responsible for the production of active IL-1 $\beta, 5,6$ a multifunctional cytokine that affects nearly every cell type and plays a central role in inflammation and associated pathological conditions. ${ }^{7}$ IL-1 $\beta$ is initially synthesized as an inactive precursor molecule (prolL-1 $\beta$ ) that lacks a signal peptide and hence remains inside the cell. ${ }^{7}$ Several enzymes are capable of processing prolL- $1 \beta$ into an active mature molecule. ${ }^{8}$ Among these, ICE cleaves the inactive
$31 \mathrm{kDa}$ precursor after Asp116, releasing the $17.5 \mathrm{kDa}$ mature form of the cytokine. ${ }^{9}$ Mature IL- $1 \beta$ is then secreted in the extracellular compartment via a nonclassical secretory pathway that seems to involve exocytosis of lysosomalrelated organelles. ${ }^{10}$

The evidence that ICE plays a dominant role in the generation of mature IL-1 $\beta$ was derived from mice deficient in this enzyme, which are overtly normal but have a major defect in the production of $\mathrm{IL}-1 \beta$ after stimulation with lipopolysaccharide (LPS), and are resistant to endotoxic shock. ${ }^{11}$ Cells from most tissues in ICE-deficient animals undergo apoptosis normally, hence questioning a consistent proapoptotic function of this caspase.$^{11}$ ICE is not able to process $\mathrm{IL}-1 \alpha{ }^{12}$ However, IL- $1 \alpha$ production is also impaired in these mice, ${ }^{12}$ suggesting a possible indirect role of ICE in IL-1 $\alpha$ production.

X-ray diffraction of the crystal structure of ICE revealed a homodimer composed of two p20/p10 heterodimers. ${ }^{13}$ These subunits are derived from a p45 ICE precursor by proteolytic cleavage at Asp residues 103, 119, 297 and $316 ; ;^{13,14}$ although recombinant ICE is capable of processing and activating itself at concentrations of $4.4 \mu \mathrm{M}$ or more, it is unlikely that this represents the mechanism responsible for ICE activation in vivo, since the level of proICE is low in all cells. ${ }^{15}$ Conversely, it has been proposed that ICE activation requires caspase-11, a recently cloned murine caspase. Cells from caspase- 11 knockout mice are resistant to apoptosis induced by ICE overexpression and are defective for the production of IL- $1 \alpha$ and IL- $1 \beta$ after LPS stimulation. ${ }^{15}$ The activation of ICE in vivo is likely to be achieved through interaction with caspase-11, whose expression is highly inducible after LPS stimulation, thus pointing to this enzyme as a member of the proinflammatory subfamily of caspases. ${ }^{15}$

Although the activation of proapoptotic caspases has been extensively studied, the apical activation pathways for proinflammatory caspases remain largely unknown. The $\mathrm{N}$ terminal domain of caspase- 1 contains a caspase-recruiting domain (CARD), a conserved sequence motif of about 90 amino acids that is believed to mediate signaling through protein-protein interactions. The CARD domain is found in several other caspases, in apoptotic signaling modulators such as CED-4, C-IAP1 and C-IAP2 ${ }^{16}$ and in a number of recently characterized proteins. ${ }^{17-22}$ The CARD domain in caspases is likely to mediate the recruitment of these enzymes to upstream signaling complexes, as has been demonstrated for caspase-2 recruitment to the TNFRITRADD-RIP complex by the CARD-containing molecule RAIDD. ${ }^{23}$

A new molecule with serine/threonine kinase activity that specifically interacts with the CARD domain of caspase-1 has been recently identified and named CARDIAK. ${ }^{24}$ Interestingly, CARDIAK can bind in vivo both TRAF1 and TRAF2, adaptor molecules involved in the generation of 
$\mathrm{NF}-\kappa \mathrm{B}$ and Jun $\mathrm{N}$-terminal kinase signaling by TNFR family members. When coexpressed with ICE in 293T cells, CARDIAK leads to the formation of the p20 active subunit of this caspase, suggesting that it may play a role in ICE recruitment to the signaling cascade of TNFR family members. ${ }^{24}$

ICE overexpression leads to apoptotic cell death, and ICE activation has been observed in some pathological conditions characterized by enhanced apoptosis, including amyotrophic lateral syndrome ${ }^{25}$ and ischemic damage. ${ }^{26}$ Thus, it is of interest to evaluate whether ICE activity in IL$1 \beta$ producing cells is always associated with apoptosis or it is compatible with cell survival.

Some reports have indeed demonstrated a correlation between $\mathrm{IL}-1 \beta$ production and apoptosis of the producing cell. In macrophages infected with Shigella flexneri, the bacterial protein IpaB binds directly to ICE and induces IL-1 $\beta$ release concomitantly with apoptotic death. ${ }^{27,28} \mathrm{IL}-1 \beta$ secretion by macrophages has also been observed during cell death consequent to interaction with $\mathrm{CD}^{+} \mathrm{T}$ cells, ${ }^{29}$ treatment with silica, ${ }^{30}$ extracellular ATP and possibly LPS. ${ }^{29}$

Nevertheless, apoptosis does not seem to be a requirement for the processing and release of $\mathrm{IL}-1 \beta$. In addition to the well investigated properties of IL-1 $\beta$ as an autocrine growth factor for acute myeloid leukemia cells, ${ }^{31}$ many studies have reported the production of $\mathrm{IL}-1 \beta$ by nonapoptotic cells. Murine monocytes that migrate into Peyer's patches during inflammation produce IL-1 $\beta$ before they mature into inflammatory macrophages. ${ }^{32} \mathrm{~A}$ fraction of human hematopoietic progenitor cells has been shown to secrete $\mathrm{IL}-1 \beta$, proliferate and differentiate into multiple lineages. $^{33}$ Moreover, enhanced $\mathrm{IL}-1 \beta$ production has been observed to correlate with prolonged longevity of peripheral blood monocytes in vitro. ${ }^{34}$ Taken together, these data suggest that ICE activation and apoptosis are not necessarily linked although they may occur concomitantly in many inflammatory conditions.

Along with the involvement of caspase-1 in inflammation and its possible role in apoptosis, an intriguing antiapoptotic activity of this caspase has been recently reported. In human polymorphonuclear neutrophils ICE-dependent cleavage of prolL-1 $\beta$ results in a delay of programmed cell death that is abrogated by blocking IL-1 $\beta$ activity with antisense oligonucleotides or with IL-1 $\beta$ antagonist antibodies. $^{35}$ These findings suggest a possible protective action exerted by ICE through the processing of $\mathrm{IL}-1 \beta$, which would act in an autocrine manner as an inhibitor of spontaneous neutrophil apoptosis during inflammation.

The pivotal role of caspase-1 in the regulation of proinflammatory networks has been strengthened by the demonstration that this caspase processes and activates prolL-18 to yield the mature form of the cytokine. ${ }^{36} \mathrm{IL}-18$ (previously called IGIF, Interferon- $\gamma$ Inducing Factor), is a novel cytokine that plays an important role in the Th1 response, primarily by its ability to induce IFN- $\gamma$ production in $\mathrm{T}$ cells and natural killer cells. ${ }^{37}$ Caspase- 1 processes prolL-18 and prolL-1 $\beta$ with equivalent efficacy in vitro, and caspase- 1 inhibitors block both LPS-induced IL-1 $\beta$ and IFN$\gamma$ production in mononuclear cells. ${ }^{36}$ Furthermore, ICE ${ }^{-1-}$ mice show a defect in LPS-induced IFN- $\gamma$ production. ${ }^{36}$
These results implicate caspase- 1 in the physiological production of IL-18 and point to specific caspase-1 inhibitors as possible multipotent anti-inflammatory drugs, which may be potentially useful in many pathological conditions. Peptidyl ICE inhibitors have been shown to reduce $\mathrm{IL}-1 \beta$ serum levels and disease severity in a mouse model of rheumatoid arthritis, ${ }^{38}$ and may prove to be helpful for the treatment of other inflammatory or autoimmune diseases in which IL-1 $\beta$ has been shown to be an important mediator. ${ }^{39,40}$

\section{A nonapoptotic role for proapoptotic caspases?}

It may be difficult to imagine a physiological role for caspase3-like proteases outside of the apoptotic pathway, since the large majority of the studies concerning caspases of the CPP32 subfamily have highlighted the relationship between their activation and the onset of cell death. This is not the case of a recent report on the role of $\mathrm{Hsp} 70,{ }^{41}$ an anti-apoptotic protein which has been shown to have a protective function against stress and a number of apoptotic stimuli. Hsp70overexpressing cells have been observed to respond to apoptotic stimuli by activation of stress-activated protein kinases, generation of free radicals, early disruption of mitochondrial transmembrane potential, release of cytochrome $\mathrm{c}$ from mitochondria and activation of caspase-3-like proteases; however, they show a strong reduction in apoptosis levels following treatment with TNF, staurosporine and doxorubicin. ${ }^{41}$ Notably, these cells are able to regain a normal growth rate in spite of the cytochrome $c$ efflux and the cleavage of caspase substrates such as PARP, PKC $\delta$ and $\mathrm{CPLA}_{2}{ }^{41}$ Although other studies are required to demonstrate the relevance of these data, these results may indicate that the 'point of no return' in the apoptotic pathway can be downstream of caspase activation.

A first report by Miossec et al, describing caspase-3 activation in PHA-stimulated T lymphocytes in the absence of apoptosis, ${ }^{42}$ became the starting point for an interesting debate on a possible nonapoptotic function of the best characterized and most efficient executioner of the apoptotic process. In this work, Western blotting experiments showed that the caspase-3 precursor is massively cleaved into the active form during early stages of $\mathrm{T}$ lymphocyte proliferation in the absence of detectable cell death. ${ }^{42}$

New findings come later to support the participation of caspase-3 like proteases in T-cell activation. The activation of caspase-3-like enzymes in the absence of apoptosis has been once again detected in $\mathrm{T}$ lymphocytes stimulated with mitogens and IL-2, and measured in cell extracts from spleen and lymph nodes of mice injected with superantigen. $^{43}$ This caspase activity associated with $T$ cell activation and proliferation was much higher than that found in tumor cells undergoing apoptosis, ${ }^{43}$ suggesting the presence of a strongly effective checkpoint downstream of caspases that would inhibit the inappropriate and premature death of the cell.

Contrasting results were obtained by another group, which was unable to observe caspase- 3 activation in mitogen-stimulated $T$ cells, both in intact cells and in 
Western blotting experiments performed with a cell lysis method that avoids secondary caspase activation following mechanical cell disruption. ${ }^{44}$ Those findings led the authors to hypothesize that post-lysis release of granzyme B or a related serine protease with specificity for aspartic acid may be responsible for an artifactual activation of caspase-3. In line with this hypothesis, they showed that a specific inhibitor of granzyme B was able to inhibit the post-lysis processing of caspase-3 without interfering with a pre-lysis activation that is found in cells undergoing apoptosis. ${ }^{44}$

Nevertheless, these discrepancies remain unsolved, as demonstrated by a recent paper that shows the occurrence of a caspase-3-like activity in PHA-stimulated Jurkat T-cells in the absence of apoptosis, ${ }^{45}$ using buffer conditions that should avoid post-lysis granzyme B-mediated activation of caspases. Moreover, experiments with caspase inhibitors on intact activated Jurkat cells support the hypothesis that a caspase-3-like activity is necessary for IL-2 release. ${ }^{45}$ However, since IL-2 is not directly activated by proteolytic cleavage, the role of caspase- 3 in the biochemical pathway that leads to IL-2 release remains enigmatic.

An interesting support to the hypothesis that caspase-3 activation occurs in living cells comes from the studies on interleukin-16 maturation in T cells. IL-16 is a pleiotropic inflammatory cytokine secreted predominantly by $\mathrm{CD}^{+}$ lymphocytes, which exerts chemoattractant and growth factor activity towards lymphocytes, monocytes and eosinophils. ${ }^{46}$ IL-16 precursor protein is processed by caspase-3 (and possibly by other caspases with similar specificity) and released as biologically active mature IL$16 .{ }^{47}$ Interestingly, IL-16 production, along with caspase-3 activation, has been detected in both resting and activated $\mathrm{CD}^{+} \mathrm{T}$ cells and in activated $\mathrm{CD} 4^{+} \mathrm{T}$ cells, without any apparent sign of apoptosis. ${ }^{48}$

Activated caspase- 3 has also been purified from the cytosol of monocytic THP-1 cells, where it is supposed to act as an 'IL-18 degrading enzyme' which cleaves both precursor and mature IL-18 to generate biologically inactive products. $^{49}$

These findings suggest again that, although caspase-3 is an important mediator of apoptotic signals, it may have other functions in addition to that of apoptotic executioner.

A possible, yet far from certain, role for caspases in the biochemical events that regulate cell proliferation is suggested by caspase-mediated processing of proteins involved in the control of cell cycle progression. Cleavage of $\mathrm{Rb},{ }^{50}$ PAK2, ${ }^{51}$ DNA-replication complex, ${ }^{52}$ an element of PITSLRE kinase ${ }^{53}$ and cyclin A2 (Xenopus), ${ }^{54}$ has been observed only during the onset of apoptosis, but it might also occur as a regulatory mechanism under different circumstances in the life of a cell. Moreover, several caspase-3 substrates increase their activity after proteolytic cleavage. ${ }^{55}$ These substrates include members of the MAP kinase family and Ras-related G-proteins, ${ }^{55}$ which are known to play a role in T-cell activation. ${ }^{56}$ However, since the cell cycle is normal in nematodes defective for the ced-3 gene, ${ }^{57}$ a hypothetical function for caspases in the regulation of cell cycle events should have evolved recently.

Caspase-mediated processing of $\mathrm{MDM} 2-\mathrm{a}$ negative regulator of the p53 tumor suppressor-has been observed in human tumor cell lines in the absence of apoptosis. ${ }^{58}$ MDM2 processing has been shown to occur prior to the onset of apoptosis and to be mediated by a DVPDcleavage activity distinct from caspase-3, -6 and -8 . MDM2 cleavage yields a $60 \mathrm{kDa}$ product that is still able to bind p53 but loses the capacity to promote p53 degradation, and hence may potentially function in a dominant-negative fashion to stabilize p53 before commitment to cell death. ${ }^{59}$

The potential role of caspases in the regulation of activation- and proliferation-related cellular events is possibly obscured by knockout mice models, since the majority of these animals display premature lethality due to profound abnormalities in development. ${ }^{60-63}$ More information should be obtained through the creation of mice expressing inducible or tissue-restricted dominant negative forms of caspases, through specific ablation of caspase genes in adult tissues and organs or through controlled expression of protein caspase inhibitors.

\section{A role for caspases in the regulation of differentiation}

When rodent lens epithelial cells terminally differentiate into anucleate lens fibers, at least one member of the caspase-3 subfamily becomes activated and mediates the characteristic cytological changes that lead to fiber formation. ${ }^{64}$ This process is promoted by fibroblast growth factor, a multifunctional growth factor required for lens fiber differentiation and protection from apoptosis. ${ }^{65}$ Lens fiber differentiation is not an apoptotic process, since differentiating cells do not shrink, nor do they become fragmented or phagocytosed by neighboring cells. By contrast, lens fibers elongate, fill up with crystallins and persist for the lifetime. However, nucleus degeneration during lens fiber development seems to share some features with the nuclear events occurring during apoptosis. Thus, terminal differentiation of lens fibers may be regarded as an incomplete apoptotic process mediated by proapoptotic caspases (Figure 1).

A novel functional role for caspases in the regulation of differentiation has recently emerged from studies on the interference of death receptors (DR)-mediated signals with erythroblast maturation.

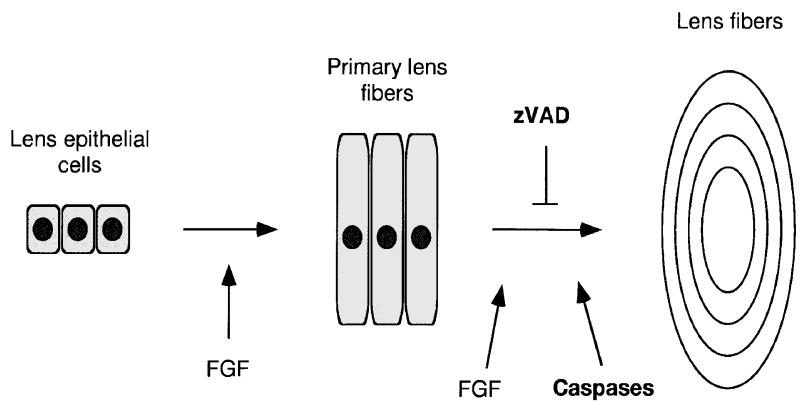

Figure 1 A pro-differentiative role for caspases. Caspases and fibroblast growth factor (FGF) are required for terminal differentiation of lens fibers, which during this process elongate and extrude the nucleus 
Stimulation of immature erythroblasts with low doses of an agonist anti-CD95 (Fas/Apo-1) antibody strongly inhibits erythroid cell expansion and differentiation without inducing detectable signs of apoptosis. Interestingly, CD95-induced differentiation arrest is associated with proteolytic degradation of the major erythroid transcription factor GATA-1, ${ }^{66}$ which is cleaved in vitro and in vivo by caspase-3, caspase-7 and caspase-8. ${ }^{67}$ Importantly, expression in immature erythroblasts of a mutant caspase-resistant GATA-1, but not of the wild-type protein, is able to completely overcome the antiproliferative and anti-differentiative effects mediated by CD95, thus providing evidence that caspase-mediated cleavage of GATA-1 is responsible for CD95-mediated blockade of erythroid differentiation. ${ }^{67}$

The ligands for CD95 and other DR are expressed on mature erythroblasts, which surround immature erythroblasts inside the erythroblastic islands before entering into blood vessels as erythrocytes. ${ }^{67,68}$ Thus it is possible that, in physiological conditions, accumulation of DR ligands expressing mature erythroblasts may temporarily inhibit the expansion and differentiation of immature DR-sensitive erythroblasts through caspase-mediated GATA-1 down- modulation that follows DR triggering. Accordingly, exogenous expression in erythroid progenitors of proteins able to block DR signaling completely abolishes GATA-1 cleavage and overcomes impaired erythroid differentiation triggered by mature erythroblast accumulation. ${ }^{67}$

Red blood cell production is promoted by erythropoietin (Epo), a glycoprotein hormone produced by the kidney in response to tissue hypoxia. Because Epo is required for erythroid cell survival, proliferation and differentiation, a decrease in Epo levels represents a major negative control mechanism in erythropoiesis. ${ }^{69}$ We recently found that preventing caspase-mediated GATA-1 cleavage is able to significantly protect immature erythroblasts from apoptosis and differentiation arrest following Epo deprivation, ${ }^{67}$ suggesting that caspase-mediated GATA-1 cleavage is involved as a general mechanism in the negative regulation of erythropoiesis (Figure 2A).

The antidifferentiative role of caspases in hematopoietic cells is further supported by the observation that anti-CD95 antibodies induce caspase-mediated differentiation arrest in megakaryocytic cells. ${ }^{67}$ In these cells, impaired progression through differentiation is associated with cleavage of NF-E2 and GATA-1, ${ }^{67}$ the two transcription factors known to be

A

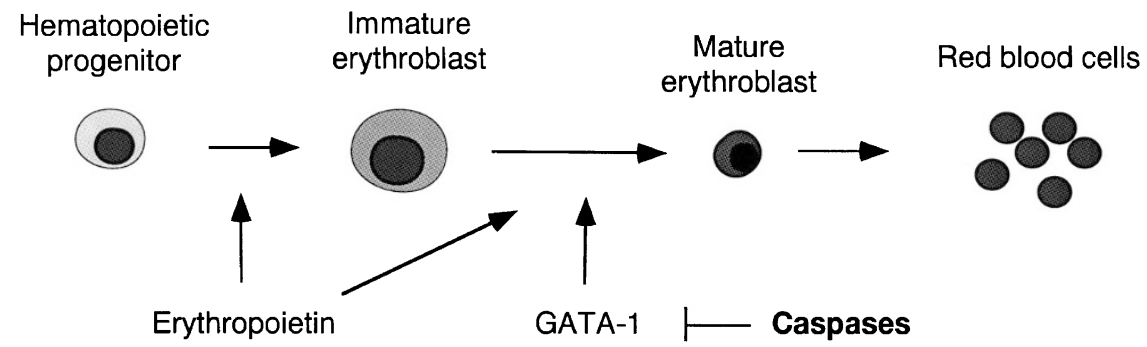

B

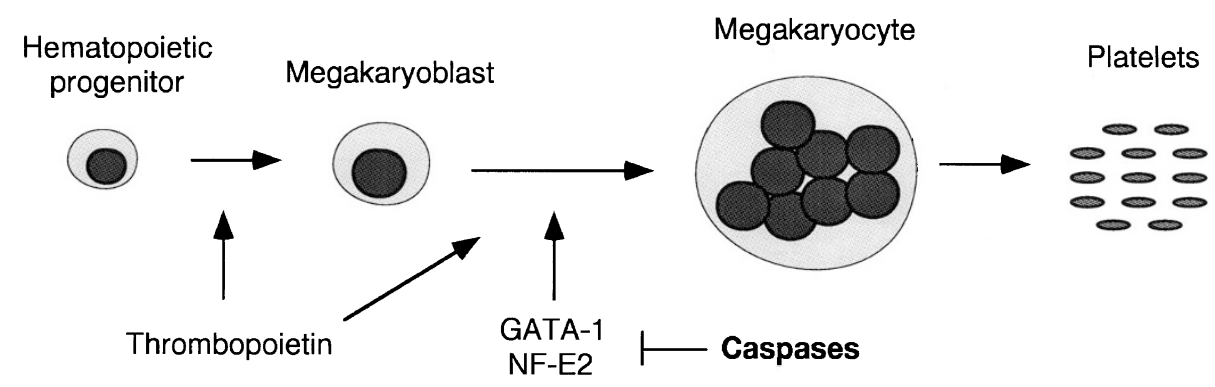

Figure 2 Caspases block hematopoietic cell differentiation. (A) Caspase activation counteracts the positive effects of erythropoietin during erythroblast development through cleavage of the transcription factor GATA-1, blocking the differentiation of immature erythroid cells. (B) Caspase activation arrests megakaryocytopoiesis through cleavage of the transcription factor GATA-1 and NF-E2, resulting in impaired endomitosis and platelet formation 
essential for terminal megakaryocyte differentiation. ${ }^{70}$ Although the relative contribution of caspase-mediated transcription factor cleavage in CD95-induced arrested megakaryopoiesis remains to be elucidated, it is likely that GATA-1 depletion plays a major role in this process. This is easily deducible from the phenotype of GATA-1deficient megakaryocytic cells, which similarly to CD95stimulated cells fail to undergo endomitosis and show unrestrained proliferation. ${ }^{67,71}$ Thus, we propose caspasemediated cleavage of transcription factors as a new mechanism responsible for the negative regulation of megakaryopoiesis (Figure 2B).

Transcription factor cleavage by caspases in a nonapoptotic circumstance has been recently demonstrated for $\mathrm{PML} / \mathrm{RAR} \alpha$, the fusion protein associated with promyelocytic leukemia. When treated with retinoic acid, leukemic cells differentiate and PML/RAR $\alpha$ becomes cleaved by a caspase-3-like activity. ${ }^{72}$ However, the precise role of $\mathrm{PML} / \mathrm{RAR} \alpha$ cleavage during differentiation of promyelocytic cells is unclear, since treatment with caspase inhibitors efficiently blocks $\mathrm{PML} / \mathrm{RAR} \alpha$ processing without interfering in the overall differentiation process. ${ }^{72}$

In this review we have discussed possible, and in some ways unconventional, caspase functions. Nevertheless, many issues raised here await clarification. First, which would be the escape mechanism from an irreversible death commitment? Are activated caspases sequestered away from death-inducing substrates or are there unknown downstream checkpoints along the apoptotic pathway? Are as yet unknown members of the caspase family responsible for nonapoptotic functions? Although further studies are required to answer these questions, the results presented in this review suggest the existence of a physiological role for caspases, apart from that of death executioners, providing examples of a circumscribed activation of these enzymes in cells not committed to death.

\section{Acknowledgements}

This work was supported by AIRC.

\section{References}

1. Yuan J, Shaham S, Ledoux S, Ellis HM and Horvitz HR (1993) The C. elegans cell death gene ced- 3 encodes a protein similar to mammalian interleukin- 1 betaconverting enzyme. Cell 75: 641-652

2. Thornberry NA and Lazebnik Y (1998) Caspases: enemies within. Science 281 : $1312-1316$

3. Nicholson DW and Thornberry NA (1997) Caspases: killer proteases. Trends Biochem. Sci. 22: 299-306

4. Dinarello CA (1998) Interleukin-1 beta, interleukin-18, and the interleukin-1 beta converting enzyme. Ann. NY Acad. Sci. 856: 1-11

5. Cerretti DP, Kozlosky CJ, Mosley B, Nelson N, Van Ness K, Greenstreet TA, March CJ, Kronheim SR, Druck T, Cannizzaro LA, Huebner K and Black RA (1992) Molecular cloning of the interleukin-1 beta converting enzyme. Science 256: $97-100$

6. Thornberry NA, Bull HG, Calaycay JR, Chapman KT, Howard AD, Kostura MJ, Miller DK, Molineaux SM, Weidner JR, Aunins J, Elliston KO, Ayala JM, Casano FJ, Chin J, Ding GJF, Egger LA, Gaffney EP, Limjuco J, Palyha OC, Raju SM, Rolando AM, Salley JP, Yamin T-T, Lee TD, Shively JE, MacCross M, Mumford RA, Schmidt JA and Tocci MJ (1992) A novel heterodimeric cysteine protease is required for interleukin-1 beta processing in monocytes. Nature 356: $768-774$
7. Dinarello CA (1998) Interleukin-1, interleukin-1 receptors and interleukin-1 receptor antagonist. Int. Rev. Immunol. 16: 457-499

8. Fantuzzi $G$ and Dinarello CA (1999) Interleukin-18 and interleukin-1 beta: two cytokine substrates for ICE (caspase-1). J. Clin. Immunol. 19:1-11

9. Black R, Kronheim S, Sleath P, Greenstreet T, Virca GD, March C and Kupper T (1991) The proteolytic activation of interleukin-1 beta. Agents Actions Suppl. 35: $85-89$

10. Andrei C, Dazzi C, Lotti L, Torrisi MR, Chimini G and Rubartelli A (1999) The secretory route of the leaderless protein interleukin 1 beta involves exocytosis of endolysosome-related vesicles. Mol. Biol. Cell 10: 1463-1475

11. LiP, Allen H, Banerjee S, Franklin S, Herzog L, Johnston C, McDowell J, Paskind M, Rodman L, Salfeld J, Towne E, Tracey D, Wardwell S, Wei F-Y, Wong W, Kamen R and Seshadri T (1995) Mice deficient in IL-1 beta-converting enzyme are defective in production of mature IL- 1 beta and resistant to endotoxic shock. Cell 80: 401-411

12. Howard AD, Kostura MJ, Thornberry N, Ding GJ, Limjuco G, Weidner J, Salley JP, Hogquist KA, Chaplin DDS, Mumford RA Schmidt JA and Tocci MJ (1991) IL1 -converting enzyme requires aspartic acid residues for processing of the IL-1 beta precursor at two distinct sites and does not cleave 31-kDa IL-1 alpha. J. Immunol. 147: 2964-2969

13. Walker NP, Talanian RV, Brady KD, Dang LC, Bump NJ, Ferenz CR, Franklin S, Ghayur T, Hackett MC, Hammill LD, Herzog L, Hugunin M, Houy W, Mankovich JA, McGuinness L, Orlewicz E, Paskind M, Pratt CA, Reis P, Summani A Terranova M, Weich JP, Xlong L, Moller A, Tracey DE, Kamen R and Wong WW (1994) Crystal structure of the cysteine protease interleukin-1 beta-converting enzyme: a (p20/p10)2 homodimer. Cell 78: 343-352

14. Wilson KP, Black JA, Thomson JA, Kim EE, Griffith JP, Navia MA, Murcko MA, Chambers SP, Aldape RA, Raybuck SA and Livingston DJ (1994) Structure and mechanism of interleukin-1 beta converting enzyme [see comments]. Nature 370: 270-275

15. Wang S, Miura M, Jung Y, Zhu H, Li E and Juan J (1998) Murine caspase-11, an ICE-interacting protease, is essential for the activation of ICE. Cell 92: 501-509

16. Hofmann K, Bucher P and Tschopp J (1997) The CARD domain: a new apoptotic signalling motif. Trends Biochem. Sci. 22: 155-156

17. Srinivasula SM, Ahmad M, Lin JH, Poyet JL, Fernandes-Alnemri T, Tsichlis PN and Alnemri ES (1999) CLAP, a novel caspase recruitment domain-containing protein in the tumor necrosis factor receptor pathway, regulates NF-kappaB activation and apoptosis. J. Biol. Chem. 274: $17946-17954$

18. Costanzo A, Guiet $C$ and Vito $P(1999)$ C-E10 is a caspase-recruiting domaincontaining protein that interacts with components of death receptors signaling pathway and activates nuclear factor-kappaB. J. Biol. Chem. 274:20127-20132

19. Inohara N, Koseki T, del Peso L, HuY, YeeC, ChenS, Carrio R, MerinoJ, LiuD, N $J$ and Nunez G (1999) Nod1, an Apaf-1-like activator of caspase-9 and nuclear factor-kappaB. J. Biol. Chem. 274: 14560-14567

20. Koseki T, Inohara N, Chen S and Nunez G (1998) ARC, an inhibitor of apoptosis expressed in skeletal muscle and heart that interacts selectively with caspases. Proc. Natl. Acad. Sci. U.S.A. 95: $5156-5160$

21. Koseki T, Inohara N, Chen S, Carrio R, Merino J, Hottiger MO, Nabel GJ and Nunez G (1999) CIPER, a novel NF kappaB-activating protein containing a caspase recruitment domain with homology to Herpesvirus-2 protein E10. J. Biol. Chem. 274: 9955-9961

22. Yan M, Lee J, Schilbach S, Goddard A and Dixit V (1999) mE10, a novel caspase recruitment domain-containing proapoptotic molecule. J. Biol. Chem. 274: $10287-10292$

23. Duan $\mathrm{H}$ and Dixit VM (1997) RAIDD is a new 'death' adaptor molecule. Nature 385: $86-89$

24. Thome M, Hofmann K, Burns K, Martinon F, Bodmer JL, Mattmann C and Tschopp J (1998) Identification of CARDIAK, a RIP-like kinase that associates with caspase-1. Curr. Biol. 8: 885-888

25. Friedlander RM, Brown RH, Gagliardini V, Wang J and Yuan J (1997) Inhibition of ICE slows ALS in mice [letter]. Nature 388: 31

26. Hara H, Friedlander RM, Gagliardini V, Ayata C, Fink K, Huang Z, ShimizuSasamata M, Yuan J and Moskowitz MA (1997) Inhibition of interleukin 1beta converting enzyme family proteases reduces ischemic and excitotoxic neuronal damage. Proc. Natl. Acad. Sci. U.S.A. 94: 2007-2012

27. Zychlinsky A, Fitting C, Cavaillon JM and Sansonetti PJ (1994) Interleukin 1 is released by murine macrophages during apoptosis induced by Shigella flexneri. J. Clin. Invest. 94: 1328-1332 
28. Chen Y, Smith MR, Thirumalai K and Zychlinsky A (1996) A bacterial invasion induces macrophage apoptosis by binding directly to ICE. EMBO J. 15: $3853-$ 3860

29. Hogquist KA, Nett MA, Unanue ER and Chaplin DD (1991) Interleukin 1 is processed and released during apoptosis. Proc. Natl. Acad. Sci. U.S.A. 88: 8485-8489

30. Sarih M, Souvannavong V, Brown SC and Adam A (1993) Silica induces apoptosis in macrophages and the release of interleukin-1 alpha and interleukin1 beta. J. Leukoc. Biol. 54: 407-413

31. Cozzolino F, Rubartelli A, Aldinucci D, Sitia R, Torcia M, Shaw A and Di Guglielmo R (1989) Interleukin 1 as an autocrine growth factor for acute myeloid leukemia cells. Proc. Natl. Acad. Sci. U.S.A. 86: 2369-2373

32. BeuscherHU, RauschUP, Otterness IG and Rollinghoff M(1992) Transition from interleukin 1 beta (IL-1 beta) to IL-1 alpha production during maturation of inflammatory macrophages in vivo. J. Exp. Med. 175: 1793-1797

33. Watari K, Mayani H, Lee F, Dragowska W, Lansdorp PM and Schrader JW (1996) Production of interleukin 1 beta by human hematopoietic progenitor cells. J. Clin. Invest. 97: 1666-1674

34. Fries G, Perneczky A and Kempski O (1994) Enhanced interleukin-1 beta release and longevity of glioma-associated peripheral blood monocytes in vitro. Neurosurgery 35: 264-270

35. William R, Watson G, Rotstein OD, Parodo J, Bitar R and Marshall JC (1998) The $\mathrm{IL}-1$ beta-converting enzyme (caspase-1) inhibits apoptosis of inflammatory neutrophils through activation of IL-1 beta. J. Immunol. 161: 957-962

36. Ghayur T, Banerjee S, Hugunin M, Butler D, Herzog L, Carter A, Quintal L, Sekut L, Talanian R, Paskind M, Wong W, Kamen R, Tracey D and Allen H (1997) Caspase-1 processes IFN-gamma-inducing factor and regulates LPS-induced IFN-gamma production. Nature 386: $619-623$

37. Dinarello CA (1999) IL-18: a TH1-inducing, proinflammatory cytokine and new member of the IL-1 family. J. Allergy Clin. Immunol. 103: 11-24

38. Ku G, Faust T, Lauffer LL, Livingston DJ and Harding MW (1996) Interleukin-1 beta converting enzyme inhibition blocks progression of type ll collagen-induced arthritis in mice. Cytokine 8: $377-386$

39. Dinarello CA and Wolff SM (1993) The role of interleukin-1 in disease. N. Engl. J. Med. 328: 106-113

40. De Maria R and Testi R (1998) Fas-FasL interactions: a common pathogenetic mechanism in organ-specific autoimmunity. Immunol. Today 19: 121-125

41. Jaattela M, Wissing D, Kokholm K, Kallunki T and Egeblad M (1998) Hsp70 exerts its anti-apoptotic function downstream of caspase-3-like proteases. EMBO J. 17: 6124-6134

42. Miossec C, Dutilleul V, Fassy F and Diu-Hercend A (1997) Evidence for CPP32 activation in the absence of apoptosis during T lymphocyte stimulation. J. Biol. Chem. 272: $13459-13462$

43. Wilhelm S, WagnerH andHacker G(1998) Activation of caspase-3-like enzymes in non-apoptotic T cells. Eur. J. Immunol. 28: 891-900

44. Zapata JM, Takahashi R, Salvesen GS and Reed JC (1998) Granzyme release and caspase activation in activated human T-lymphocytes. J. Biol. Chem. 273: 6916-6920

45. Postmantur R, Wang KK and Gilbertsen RB (1998) Caspase-3-like activity is necessary for IL-2 release in activated Jurkat T-cells. Exp. Cell. Res. 244: $302-$ 309

46. Center DM, Kornfeld H and CruikshankWW(1996) Interleukin 16 and its function as a CD4 ligand. Immunol. Today 17: 476-481

47. Zhang Y, Center DM, Wu DM, Cruikshank WW, Juan Y, Andrews DW and Kornfeld H (1998) Processing and activation of pro-interleukin- 16 by caspase-3. J. Biol. Chem. 273: 1144-1149

48. Wu DM, Zhang Y, Parada NA, Kornfeld H, Nicoll J, Center DM and Cruikshank WW (1999) Processing and release of IL-16 from CD4+ but not CD8+ T cells is activation dependent. J. Immunol. 162: 1287-1293

49. Akita K, Ohtsuki T, Nukada $Y$, Tanimoto T, Namba M, Okura T, TakakuraYamamoto R, Torigoe K, Gu Y, Su MSS, Fujii M, Satoh-Itoh M, Yamamoto K, Kohno K, Ikeda M and Kurimoto M (1997) Involvement of caspase-1 and caspase- 3 in the production and processing of mature human interleukin 18 in monocytic THP. 1 cells. J. Biol. Chem. 272: 26595-26603

50. Janicke RU, Walker PA, Lin XY and Porter AG (1996) Specific cleavage of the retinoblastoma protein by an ICE-like protease in apoptosis. EMBOJ. 15:69696978
51. Rudel T and Bokoch GM (1997) Membrane and morphological changes in apoptotic cells regulated by caspase-mediated activation of PAK2. Science 276 : $1571-1574$

52. Rheaume E, Cohen LY, Uhlmann F, Lazure C, Alam A, Hurwitz J, Sekaly RP and Denis $F(1997)$ The large subunit of replication factor $C$ is a substrate for caspase3 in vitro and is cleaved by a caspase- 3 like protease during Fas-mediated apoptosis. EMBO J. 16: 6346-6354

53. Beyaert R, Kidd VJ, Cornelis S, Van de Craen M, Denecker G, Lahti JM, Gururajan R, Vandenabeele P and Fiers W (1997) Cleavage of PITSLRE kinases by ICE/CASP-1 and CPP32/CASP-3 during apoptosis induced by tumor necrosis factor. J. Biol. Chem. 272: 11694-11697

54. Stack JH and Newport JW (1997) Developmentally regulated activation of apoptosis early in Xenopus gastrulation results in cyclin A degradation during interphase of the cell cycle. Development 124: 3185-3195

55. Widmann C, Gibson S and Johnson GL (1998) Caspase-dependent cleavage of signaling proteins during apoptosis. A turn-off mechanism for anti-apoptotic signals. J. Biol. Chem. 273: 7141-7147

56. Zenner G, Dirk zur Hausen J, Burn P and Mustelin T (1995) Towards unraveling the complexity of T cell signal transduction. Bioessays 17: 967-975

57. Ellis HM and Horvitz HR (1986) Genetic control of programmed cell death in the nematode C. elegans. Cell 44: 817-829

58. Honda R, TanakaHand Yasuda H(1997) Oncoprotein MDM2 is a ubiquitin ligase E3 for tumor suppressor p53. FEBS Lett. 420: 25-27

59. Pochampally R, Fodera B, Chen L, Lu W and Chen J (1999) Activation of an MDM2-specific caspase by p53 in the absence of apoptosis. J. Biol. Chem. 274: $15271-15277$

60. Kuida K, Zheng TS, Na S, Kuan C, Yang D, Karasuyama H, Rakic P and Flavell RA (1996) Decreased apoptosis in the brain and premature lethality in CP32deficient mice. Nature 384: 368-372

61. Kuida K, Haydar TF, Kuan CY, GuY, Taya C, Karasuyama H, Su MS, Rakic P and Flavell RA (1998) Reduced apoptosis and cytochrome c-mediated caspase activation in mice lacking caspase 9. Cell 94: 325-337

62. Hakem R, Hakem A, Duncan GS, Henderson JT, Woo M, Soengas MS, Elia A, de la Pompa JL, Kagi D, Khoo W, Potter J, Yoshida R, Kaufman SA, Lowe SW, Penninger JM and Mak TW (1998) Differential requirement for caspase 9 in apoptotic pathways in vivo. Cell 94: 339-352

63. Varfolomeev EE, Schuchmann M, Luria V, Chiannilkulchai N, Beckmann JS, Mett IL, Rebrikov D, Brodianski VM, Kemper OC, Kollet O, Lapidot T, Soffer D, Sobe T, Avraham KB, Goncharov T, Holtmann H, Lonai P and Wallach D (1998) Targeted disruption of the mouse Caspase 8 gene ablates cell death induction by the TNF receptors, Fas/Apo 1, and DR3 and is lethal prenatally. Immunity 9:267276

64. Ishizaki Y, Jacobson MD and Raff MC (1998) A role for caspases in lens fiber differentiation. J. Cell. Biol. 140: 153-158

65. Lang RA (1997) Apoptosis in mammalian eye development: lens morphogenesis, vascular regression and immune privilege. Cell Death Differ. 4: 12-20

66. Weiss MJ and Orkin SH (1995) Transcription factor GATA-1 permits survival and maturation of erythroid precursors by preventing apoptosis. Proc. Natl. Acad. Sci. U.S.A. 92: 9623-9627

67. De Maria R, Zeuner A, Eramo A, DomenichelliC, BonciD, GrignaniF, Srinivasula SM, Alnemri ES, Testa U and Peschle C (1999) Negative regulation of erythropoiesis by caspase-mediated cleavage of GATA-1. Nature 401: 489493

68. De Maria R, Testa U, Luchetti L, Zeuner A, Stassi G, Pelosi E, Riccioni R, Felli N, Samoggia P and Peschle C (1999) Apoptotic role of Fas/Fas ligand system in the regulation of erythropoiesis. Blood 93: 796-803

69. Krantz SB (1991) Erythropoietin. Blood 77: 419-434

70. Shivdasani RA, Rosenblatt MF, Zucker-Franklin D, Jackson CW, Hunt $P$, Saris CJ and Orkin SH (1995) Transcription factor NF-E2 is required for platelet formation independent of the actions of thrombopoietin/MGDF in megakaryocyte development. Cell 81: 695-704

71. Vyas P, AultK, Jackson CW, Orkin SHand Shivdasani RA (1999)Consequences of GATA-1 deficiency in megakaryocytes and platelets. Blood 93: 2867-2875

72. Nervi C, Ferrara FF, Fanelli M, Rippo MR, Tomassini B, Ferrucci PF, Ruthard M, Gelmetti V, Gambacorti-Passerini C, Diverio D, Grignani F, Pelicci PG and Testi R (1998) Caspases mediate retinoic acid-induced degradation of the acute promyelocytic leukemia PML/RARalpha fusion protein. Blood 92: 2244-2251 